
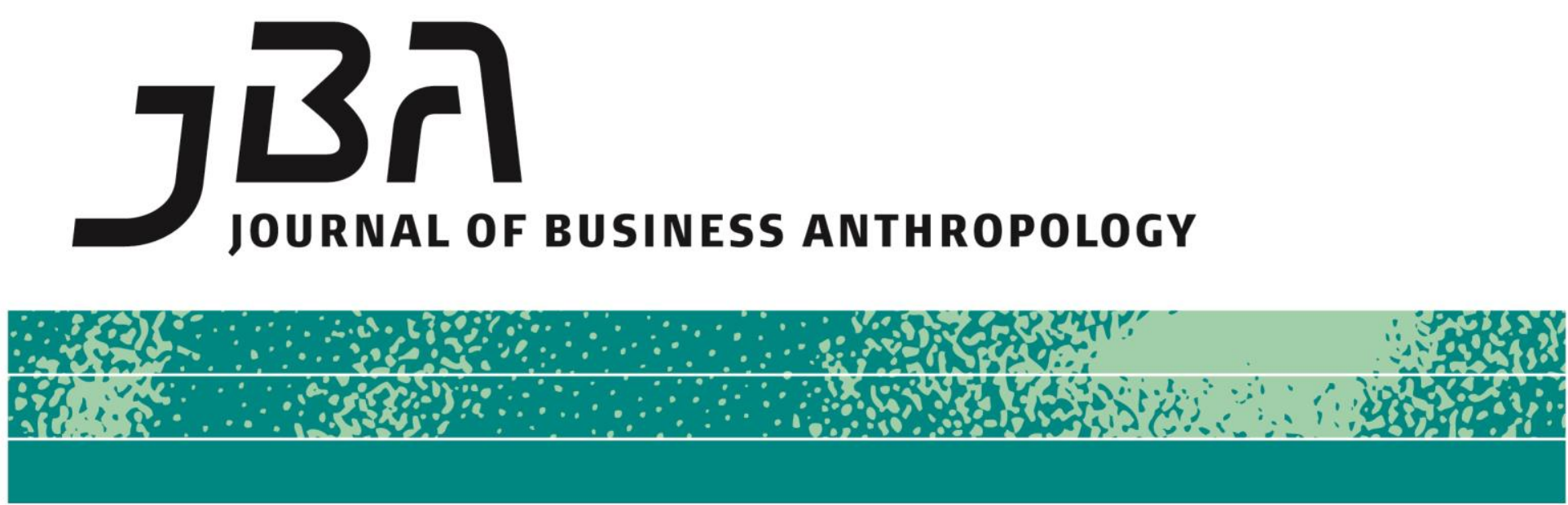

\title{
Essay \\ Google, Humanistic Anthropology and Smartphone Play
}

\author{
Thomas Maschio
}

\section{Background}

Some months ago Google approached me to ask how I might frame a study of the meaningful dimensions of smart phone, tablet, and computer use. They were also interested in my take on the power and meaning of visual imagery in the digital space.

After a few preliminary interviews I began to see that the subfield of anthropology called humanistic anthropology offered insightful ideas and approaches to my study problem. Humanistic anthropology draws on the humanities-aesthetic and literary theory, ideas about play and culture, philosophical ideas about patterns in culture, phenomenology-to understand the meanings of human behaviors

Google is a great technical company, data-driven, design- and engineering-centric. But they felt that for all their studies and quantitative measurements of customer usage of mobile devices, the human meanings of what people were up to, in all its depth and quotidian profundity, were somehow eluding them. And so we have carried out two projects so far in an initiative called: the "Humanizing Digital Project." Of
Page 1 of 8

JBA 3(2): 238-245

Fall 2014

(C) The Author(s) 2014

ISSN 2245-4217

www.cbs.dk/jba 
course people have been beating Google to the punch. They have been "humanizing" digital technologies from the get-go. People attribute meanings and dimensions to all technologies and phenomena they encounter. Humanistic anthropology is the study of these meanings.

I want to give a few brief examples here of how the humanistic approach helped me to talk about the meaningful dimensions of the new digital technologies, devices and spaces. ${ }^{1}$ First, I drew on anthropological and philosophical ideas about play. In fact I've often drawn on anthropological ideas about play and games to help me understand the particular pleasures that products, brands and technologies give to people. The great Dutch cultural historian Johan Huizinga told us long ago that play can be a serious undertaking for people and for culture, writing that law, commerce, profit, craft and art were originally "cooked in the primeval soil of play." Certainly new cultural and social forms are being created by the new mobile technologies. Texting, photo sharing, streaming video and other content are leading to new ways of being in the world, new ways of finding meaning, value and pleasure in life. Viewing the satisfactions provided to users by Blackberries, iPhones and Droids in terms of play theory can also show us the age-old human values and proclivities that are being expressed in the smartphone user experience.

\section{Play}

A famous surviving fragment of the pre-Socratic philosopher Heraclitus: "Lifetime is like a child at play, moving pieces in a game. Kingship belongs to a child." The fragment references the idea that children create whole worlds in their play, that they are, like kings, creators of reality. It also references the idea of magical control, the child's movement of pieces in the game magically transforming some aspect of reality, sometimes seemingly obliterating the constraints of time and space. But the player does not create a world, imaginative or otherwise, out of nothing. The game referenced in the fragment was played, we would imagine, on a board and in accordance with the rules of that game. This reminds us of what students of children's play note: that players continually move between mimesis and mythos. That is, they move between the imitation (mimesis) of well-known cultural scripts (a visit to the doctor's office, a teacher's lesson) and their own invented variations on that script (mythos or story). The continual alteration between these two principles brings something new into existence: a game shaped by the child's own imagination (Goldman 1999:20).

\footnotetext{
${ }^{1} \mathrm{~A}$ discussion of the practical applications of some of the ideas we came up can be found in the Google white paper entitled: The Meaning of Mobile, found in Think with Google, http://www.thinkwithgoogle.com/insights/library/studies/the-meaning-ofmobile/
} 
When people use mobile devices, they draw upon what an anthropologist would call cultural scripts, or frames. The scripts most often used are those for toys and play. Mobile device use is characterized by the sense that one is playing with a toy. But the experience of the play of these objects is not uniform. Each player creates a new experience, or experiences his play object in a different way.

In the essay "Meditations on a Hobby Horse," E. H Gombrich writes that one of the most primal of toys is the hobby horse. As any parent will tell you, the best hobby horse is one that is a symbolic representation of a horse rather than a naturalistic one. A broomstick or mop will do, in fact, will do better than a fully-realized hobby horse. The minimum, or small image, is often the more powerful object of the child's fantasies. It provides the child with her own opportunity for imaginative elaboration, rather than short-circuiting her propensity for imaginative play by providing a too-finished, too-complete representation. The minimum image invites passage to the imaginative realm of play.

Smartphones share in this symbolism of the small image, such that users are inspired to continually elaborate and embellish their meanings and functions until the devices become baroque. These are toys that invite passage to another world of experience. As I watched users play with their devices I was reminded of the children's ballet, The Nutcracker Suite, in which an entire toy world comes alive. I thought of how the children in the ballet transition to another world, guided by the Nutcracker toy. As Susan Stewart reminds us, miniature objects and toys (a doll house, a miniature book, a model ship) and miniature places (a miniature golf course, a children's zoo) represent fantasy, reverie, imagination. They give us permission to suspend disbelief, to daydream. In the digital world, small objects such as smartphones and tablets share in the symbolism of the small. They spur our imaginations. They are toys that lend themselves to fantasy and play. The small and the miniature is the realm of childhood, yet at the same time our mobile objects are powerful tools for adults. Our study explored how these qualities of smart phones spurred exploration and what we call world building.

\section{Smartphone Scripts and Analogies: Building a Dwelling Place, the Architecture of Happiness, Mapping and Exploring a Space}

Manipulating a toy is a type of world building, as the player places an intellectual structure upon reality through play and in this way brings the cold objectivity of the world into line with his own inner disposition, inclinations and desires. The player also transitions to another space by building that space with his imagination. The apps craze, adding application upon application to one's smart phone, is a type of world building, for the purpose of emotional transport. It's worth noting that video, music and game apps are the most popular. These are play applications that promote reverie, escape and mood lightening. These 
and other applications that one finds on smartphones and tablets speak to the player's objective of surrounding the self with a beguiling world of amusement and play.

In the language of phenomenology, the game of choosing one's apps can be thought of as creating a "dwelling place" for one's spirit. Apps express the user's interests, aesthetics, personality and identity at the same time that they extend and develop these interests. Borrowing a phrase that I particularly like from Alain de Botton, I would say that the inner space of the smartphone is an "architecture of happiness." It provides a sense of solace and enjoyment to its owner just as a loved house can be considered an architecture of happiness that provides solace and enjoyment to its owner. Metaphorically speaking, different applications are like different rooms in a large house, each of which provides a different emotional satisfaction to its owner. De Botton is instructive:

"One's house can provide not only physical but psychological sanctuary. It has been a guardian of identity. Over the years its owners have returned from periods away and, on looking around them, remembered who they were. The flagstones on the ground floor speak of serenity and grace, while the regularity of the kitchen cabinets offers a model of unintimidating order and discipline. The dining table, with its waxy tablecloth printed with large buttercups, suggests a burst of playfulness, which is thrown into relief by a sterner concrete wall nearby. Along the stairs, small still-lives of eggs and lemons draw attention to the intricacy and beauty of everyday things. On a ledge beneath a window a glass jar of cornflowers helps to resist the pull toward dejection. On the upper floor, a narrow empty room allows space for restorative thoughts to hatch, its skylight giving out onto impatient clouds migrating rapidly over cranes and chimney pots

"Although this house may lack solutions to a great many of its occupants ills, its rooms never-the-less give evidence of a happiness to which architecture has made its distinctive contribution." ${ }^{2}$

Similarly, applications such as Epicurious, Nikewomen Training Club, Brushes, Helios, iBird Explorer, Slacker, Hipstamatic, Urban Spoon, Star Walk, Redlaser, etc., give evidence of an enlivening happiness, the emotional benefit of the "rooms" of the smartphone. The owner and smartphone devotee continually visits these places, as a person would enter a room she loves in her house, a room whose surrounding features lifts her mood toward a kind of happiness.

As the rooms of a house capture and express many different types

${ }^{2}$ Alain De Botton The Architecture of Happiness. New York: Vintage Books, 2006, Pg 11. 
of moods, interests and feelings, so too does the inner space of the smartphone. Viewed in this way, the smartphone is a device for emotional management as well as identity construction and identity maintenance.

\section{Self-Inscription and a Sense of the Local: Place-Making}

When a smartphone user buys another app, she sometimes cuts a path toward a new interest or concern of hers. She navigates through old paths of long-standing interest and inscribes aspects of herself, her concerns, desires, and personality on the inner space of the phone. She creates a participation in her phone, joining aspects of herself to it. This type of "customization" is really a way of making the phone a sort of mechanical avatar of the self. The smartphone user is building a metaphor of self, a sense of the self as accumulating or building over time.

This sense of self has a spatial and geographic dimension. The game of smartphone use often anchors the self in particular geographic spaces. This is one of the reasons that map and directional apps are extremely popular on these devices. Users seek to map out the local geographies they move through, searching out sites of interests and importance to them. Their own neighborhood "territories" are often the most thoroughly mapped. So we will find a date night folder on the phone, with restaurant apps (reviews and the like) of local haunts. Or we will find a folder containing apps for the local gym with a schedule of classes that can be booked online, apps for local performance venues, local event calendars, and so on. It is striking how geographically anchored, how place-bound the digital mobile life really is. As one respondent said to me:

"I have made a home in this neighborhood. It gives me a comfortable feeling. And I like to have the neighborhood, well, here on my phone. It keeps me in touch with it, with the things that are going on here that I enjoy, with the places that I like to go to."

Such thoughts indicate that the sense of the local is extremely close at hand. It is carried in hand in one's phone. But this neighborhood or local sense is selective; not everything is on there, rather only what one likes, a personal utopia always on tap. Social media and apps like Foursquare, Groupon, and LivingSocial build connections to places-neighborhoods, restaurants, bars, amusement parks, local gyms, banks, beauty salons, museums, art galleries, schools, parks, children's playgrounds-through a consensus of taste. The personal utopia is highly social.

The places of the personal utopia have emotional resonance. And so, on a hot July day, a grandfather attaches his grandson's little red wagon to the back of his lawn mower and tows the boy along on a grass and hay cutting ride. The memory of the event captures an idyllic moment of childhood that is held, encompassed by this space, a commonplace suburban back yard. The place becomes socially meaningful when a 
picture of it is sent via Instagram feed to the family's digital network, whose members subsequently comment on and feel the emotion of the scene. Or, a romantic relationship begins or ends at a particular restaurant. The place becomes redolent with the meanings of the event. In these ways places harbor our humanity, providing an emotional foundation to our lives. And, increasingly people are filling the places and physical spaces that surround them with emotions and memories through their digital devices making, as the Decemberists' song tells us, "this cold harbour home".

"My phone has over 1500 photos on it-just full of memories... For me it's capturing memories of how much fun we had at certain places...You move into a new neighborhood and begin making attachments. You associate certain places with memories, to a bar that seems fun and comfortable to you, to the bagel guy that you talk to everyday... It becomes part of your routine, giving a sense of security and attachment and community."

The concept of place making is taken from the anthropology of religion, which tells us that place making in religious practice and ritual is a type of world building. Anthropologists have shown that the process of place making represents the common desire to build meaningful worlds. We leveraged the idea of place making in our study, showing that much of the fun of the mobile life lies in the way in which places are "made" or discovered.

"I was at a Lower East Side nightclub. It was a live music bar. I checked in on Facebook, with a photo of myself at Blind Tiger Bar. I'll check into a place where I am and somebody says, oh, I just happened to go on Facebook and checked your news feed and saw where you were and made a connection and posted it there. It was a cool place. A girl I hadn't seen in two years then saw that and came by and found me. You see people, other people checking in at places, and Mike was at Dorian's Pub or at this pizzeria, you can click on that and it shows any other friends that you have and have been to that bar and have checked in. Five or six people were there, oh that place looks like a really cool bar because five or six people went there and had good social interactions, maybe you see pictures and you say to yourself, that place looks like a really cool bar. It's really cool how the social community can really steer you in that direction."

Instagramming or checking in at Foursquare or Facebook can have the effect of making a place seem more interesting-even make it come into existence for a like-minded crowd. This process is also a form of search or exploration: it is an exploration of neighborhood that is at the same time a search for community.

"I love to explore the 'hood...with Foursquare I can see where people have gone or checked in the past...a barrage of places can 
pop up on your smartphone... and it's a way of getting together with friends especially if I am in a friend's neighborhood... they see you've checked in at the VFW, there was karaoke there and the friend came by."

By making these positive spatial designations, people are constructing pictures of their local worlds and of their place within them, revealing to us their relationships to these worlds.

There is a little bit of old wine in the new digital skin. People have always needed to invest meaning in the physical places, in the geography that surrounds them, conferring meaning on the places upon which they stand. This is part of what constitutes world building. Now, many are trying to build meaningful worlds to live in through their mobile devices.

\section{New and Old Senses of Self}

People are creating and outlining social boundaries and social communities, communities of taste and shared interests, as they incorporate their favorite places into the digital space of the smartphone. This sheds light on the games of texting and picture sharing (though the meaning of visual imagery on digital space is quite complex and demands separate treatment). The practice, constant among the younger set, of texting friends information about where one is, what the scene and experience is like there, are indications of the re-emergence of a particular self concept. Anthropologists recognize the re-emergence of the relational self in many of the practices of digital culture. In fact, much digital story telling involves people trying to communicate their own uniqueness to others who share similar worldviews, tastes, habits, likes, dislikes and life situations. They speak in images that have meaning to specific types of others, one would say, to members of their own tribe.

As a point of contrast we reference the anthropologist Clifford Geertz, who wrote that Western culture views the person as a dynamic center of awareness, emotion and judgment, set apart as an individual from others. Scholars have charted the history of the individualistic concept of self-that is, they have argued that this is an historical, culturally contingent form, not a universal idea or style of self. Our study of digital culture considered how relational concepts of the self have come into a powerful dialogue with notions of individualism. Digital culture reveals how people are more and more often viewing their own lives as a reflection of the ideas, values and lives of others. It shows how people are increasingly defining themselves in relationship to others.

Emerging self-concepts were really at the heart of our study. As another example we considered how digital supports the rise of what we called the protean/flexible self-the sort of person who has learned to make it up as he or she goes along. The metaphor of quicksilver adaptability captures the central value of work and play identities 
beginning in the 60s and continuing today. Being in the quickly changing flow of life, being flexible enough for changing careers, changing jobs are the watchwords of the day. Digital technologies and practices support the softening up of work and play schedules and events, establishing new, more flexible senses of time and of routine. They encourage multitasking. They convey the experience of being connected to a current of animating, enlivening social energy that brings people to a heightened sense of serendipity. Mobile device use can open people up to the unexpected, felicitous event or experience at any moment in time. We showed how this encouraged them to be flexible enough to take advantage of such moments and events.

Tom Maschio has been a business anthropologist for the past sixteen years and head of his own consultancy (Maschio Consulting) since 2004. His consulting work has run the gamut of product and service categories and has been carried out mostly for Fortune 500 companies. His original training in symbolic and humanistic anthropology continues to undergird his approach to business anthropology. He originally carried out ethnographic research in Papua New Guinea and his experience there serves as an ongoing source of inspiration for his life and work. He can be reached at tom@maschioconsulting.com 